\title{
Erratum to: Twelve Novel Atm Mutations Identified in Chinese Ataxia Telangiectasia Patients
}

\author{
Yu Huang $\cdot$ Lu Yang $\cdot$ Jianchun Wang $\cdot$ \\ Fan Yang $\cdot$ Ying Xiao $\cdot$ Rongjun Xia $\cdot$ \\ Xianhou Yuan $\cdot$ Mingshan Yan
}

Published online: 14 September 2013

(C) Springer Science+Business Media New York 2013

Erratum to: Neuromol Med (2013) 15:536-540

DOI 10.1007/s12017-013-8240-3

The authors found two typing errors in the original published article. One missense mutation in patient CHAT8 "c.6885G $>$ T" and its protein effect "p.V1248F" which appeared on line 11 of Table 2 were incorrectly typed. They should have appeared as "c.6685G $>\mathrm{T}$ " and "p.V2229F", respectively. The authors regret these errors.

The online version of the original article can be found under doi:10.1007/s12017-013-8240-3.

Y. Huang

Department of Medical Genetics, Peking University Health,

Science Center, Beijing, China

L. Yang $\cdot$ J. Wang $\cdot$ F. Yang $\cdot$ Y. Xiao $\cdot$ R. Xia $\cdot$ X. Yuan $\cdot$

M. Yan $(\bowtie)$

Zijing Biomedical Institute, School of Medicine,

Wuhan University of Science and Technology,

820 Heping Street, Wuhan 430062, China

e-mail: mingshanyan@yahoo.com

M. Yan

Bach Pharma, Inc., 800 Turnpike Street, Suite 300,

North Andover, MA 01845, USA 